\title{
Roma Sinica and Confucius and Cicero: extending the boundaries and constructing relationships
}

This volume marks the official birth of the new De Gruyter series Roma Sinica: Mutual Interactions between Ancient Roman and Eastern Thought. ${ }^{1}$ This series ${ }^{2}$ aims to cover a gap in scholarly publishing on the relationships between Ancient Greek and Roman culture and Chinese, Korean, and Japanese thought, and to draw a more precise picture of these connections, focusing on subjects such as philology, literature, philosophy, politics. In fact, the number of studies on the historical features of the contacts between Ancient East and West has grown in recent years, as testified by certain works. ${ }^{3}$ However, even if we are satisfied with our level of knowledge of historical and economic connections, we cannot say the same for the history of thought in its various facets. For instance, ancient evidence about connections among ancient Roman, Greek, and Chinese authors is very poor. But, in the XVIIth and XVIIIth centuries, the Jesuit fathers, such as Ricci, Intorcetta, and Longobardi, described and discussed in many passages of their books the thought of Chinese philosophers and writers by using their own cultural memories as cultivated Western men. These writers were well-versed not only in Christian texts and the Vulgate, but also in Cicero, Seneca, Plutarch, and many other ancient authors. They read 'their' China, 'their' Korea, and 'their' Japan with the eyes of men deeply rooted in their culture, making comparisons - implicit or explicit - between Confucius, Meng Zhou, and Roman writers. Moreover, they composed their books in Latin and had thus to develop effective linguistic strategies to allow Western readers to understand Eastern thought. This fact authorizes us to investigate the modality, the features

1 https://www.degruyter.com/dg/newsitem/279/neue-open-accessprojekte-in-den-alter tumswissenschaften-fr-de-gruyter-

2 The directors of the series are Andrea Balbo (University of Turin) and Jaewon Ahn (Seoul National University). The Advisory Board includes Michele Ferrero (Beijing Foreign Studies University); Lee Kangjae (Seoul National University); David Konstan (New York University); Fritz-Heiner Mutschler (em. Technische Universität Dresden); Carlo Santini (Former professor of Latin Language and Literature at the University of Perugia); Alessandro Schiesaro (University of Manchester); Aldo Setaioli (em. University of Perugia); Stefania Stafutti (University of Torino).

3 Our bibliography does not aim to be exhaustive and stresses more recent texts. After the classic Ferguson (1978), we can refer, for instance, to Leslie/Gardiner (1996), Mutschler/Mittag (2008), and to the very recent Michelazzi (2018), a survey of the most important sources on the topic seen from a historian's point of view, and Renger (2018).

2 OpenAccess. (c) 2019, published by De Gruyter. (cc) BY-NC-ND This work is licensed under the Creative Commons Attribution-NonCommercial-NoDerivatives 4.0 License. https://doi.org/10.1515/9783110616804-001 
and the history of this cultural reception. With Roma Sinica, we hope to build a meaningful contribution to the composition of this history. More than just a series, Roma Sinica sets out to open new perspectives in comparative studies, taking a multidisciplinary approach within the humanities and offering scholars interested in this field an opportunity to exchange ideas, to discuss their work, and to have it published by a publisher as prestigious as De Gruyter.

The first step of this project was the international conference held in Turin on September 5-6th, 2017, with the title, "Confucius and Cicero: new ideas for an old world, old ideas for a new world." The organizers approached two pivotal figures of Eastern and Western civilization from an unusual angle. While Latin Jesuit sources seem more frequently to bring together Seneca and Confucius, papers in this volume have taken original approaches to search out connections between the two thinkers that are not always so clear.

The volume opens with an introductory section where Fritz-Heiner Mutschler (Comparing Confucius and Cicero: Problems and Possibilities) addresses the subject of the conference, examining in depth the meaning and value of an inquiry into the opportunities and limits of the comparison between Cicero and Confucius. His concluding remarks are worth noting: "The comparison between Confucius and Cicero may not be without pitfalls, but if it is done with circumspection and caution towards hasty conclusions it can teach us much, not only about the two individuals but also about the two cultures to which they belong."

The second section creates, as it were, the philosophical background from which a comparison between Confucius and Cicero can develop. Tongdong Bai (The Private and the Public in the Republic and in the Analects) draws a comparison between Plato's Republic and Confucius' Analects, two essential texts of political philosophy in Western and Eastern Culture, exploring which model can better account for the conflict between the private and the public spheres. G. Parkes (Confucian and Daoist, Stoic and Epicurean. Some Parallels in Ways of Living) looks for possible opportunities of comparison between the philosophical ideas of the Stoics, Epicureans, and Daoists. Parkes' perspective devotes great attention to modern problems of ecology and the survival of the Earth. Jungsam Yum (Mind and Ritual in the Xunzi) carefully explores the meaning of Li 禮, ritual, going beyond Confucian boundaries in order to encounter Xunzi's thought.

The third section deals with problems of translating Confucius into Latin as a means of making his thought accessible to Western readers. M. Ferrero (The Latin translations of Confucius' Dialogue - Lun Yu -. A comparison of key concepts), in an extensive and rich paper, examines the translation choices of key Chinese concepts into Latin proposed by Ruggieri, Couplet, Zottoli, Cheung, and other translators from the end of XVIth century. Jaewon Ahn (Is Confucius a Sinicus Cicero?) reflects on the character of the Latin translations of some Chi- 
nese treatises in the Confucius Sinarum Philosophus sive Scientia Sinensis, published by order of Louis XIV in Paris in 1687. His conclusion supports the significant role played by this book in the reception of Chinese culture in the West.

The fourth section tackles the problem of examining some key concepts which are of great importance both in Ciceronian and in Confucian thought, even if they are expressed in very different ways. Christian Hoegel (Humanitas: Universalism, equivocation, and basic criterion) examines the essential elements of the Roman - and Ciceronian - doctrine of humanitas, accurately highlighting its features and limitations. Stéphane Mercier (Becoming human(e): Confucius' Way to 仁 and the Imitation of Christ in Yi Byeok's Essence of Sacred Doctrine (聖呚要旨; Seonggyo yoji) deals with the concept of ren, the meaning of which is in some ways quite close to that of humanitas. This is a unique study, making particular reference to Korean scholars who converted to Christianity. Kihoon Kim (Pietas in pro Sexto Roscio of Cicero and Confucian 孝 xiao) works on the problem of pietas in the Ciceronian speech. He compares it with the idea of Confucian xiao, underlining the closeness of the two ideas. Stefania Stafutti ("Be modest and avoid wastefulness": table manners and beyond from Confucius to $X i$ Jinping) reflects from a contemporary perspective on the role of the 'old Master' in the politics of China enacted by modern leaders such as Xi Jin Ping (and others).

The final paper, which forms an ideal ring composition with Mutschler's introduction, is offered by Yasunari Takada (Cicero and Confucius: Similitude in Disguise). Takada shows how the similarities and the dissimilarities between the two philosophers should be explained by taking into consideration the cultural differences and their respective roles in the building of the civilizations of West and East, although Confucius' role in this regard appears stronger than Cicero's. ${ }^{4}$

As demonstrated by its contents, this volume aims more to raise questions than to offer definitive solutions: further inquiries - the first to take place in Seoul in 2019, under the title "Empire and Politics in Eastern and Western Civilization" - will enrich the colors of the fresco and provide new opportunities for comprehending the role of antiquity in forming modern civilization. However, this is another story, and still to be written.

One must remember here that this project and the related conferences would not have been possible without the generous support of many sponsors: among them we should mention the SIAC (International Society of Cicero's friends), Daewon Food Inc, the University of Turin, the Confucius Institute of the Univer-

4 We want to thank also J.L. Ferrary and A. Andreini, who gave interesting papers in Turin, but, for different reasons, could not transform their communications into revised articles. 
sity of Turin (with the pivotal aid of S. Stafutti), and the Seoul National University.

Special thanks also goes to the generosity of friends, colleagues, and students who helped to make for enjoyable days in Turin, taking an active part in the organization. We give particular thanks to Ermanno Malaspina, Simone Mollea, Elisa Della Calce, and Philippe Rousselot. We also express our gratitude to the members of the De Gruyter staff, Serena Pirrotta and Marco Michele Acquafredda, who made a decisive contribution to the publication of the volume.

At the close of this introduction the final thanks are due to Cicero and Confucius. It comes from two humble famuli of their wisdom, who once more have had the opportunity to learn something from them and also from each other, trying to introduce their findings in an accessible way to all readers who will have the patience and kindness to read this book.

Andrea Balbo

Jaewon Ahn

The Editors thank a lot Kihoon Kim and Aldo Setaioli for helping them revising the book. 